\title{
CURRENT CHARACTERISTICS IN THE PRESENCE OF NEAR-ORTHOGONAL WAVES
}

\author{
Kian Yew Lim ${ }^{1}$, Ole Secher Madsen ${ }^{2}$, Hin Fatt Cheong ${ }^{1}$
}

\begin{abstract}
An experimental study involving near-orthogonal wave-current interaction in a wave basin is reported in this paper. Due to previous shortcomings associated with 2D bottom configurations, i.e. occurrence of ripple-induced turning of flows close to the bed, the present experiments were conducted with the bottom covered by closely packed ceramic marbles (mean diameter of $1.25 \mathrm{~cm}$ ). Three types of flows were generated over this bottom: current-alone, wave-alone and combined wave-current flow. For current-alone and wave-current cases, the log-profile analysis was used to resolve the equivalent Nikuradse sand grain roughness, $\mathrm{k}_{\mathrm{n}}$, while the energy dissipation method was used to estimate $\mathrm{k}_{\mathrm{n}}$ for wave-alone case. The results show that $\mathrm{k}_{\mathrm{n}}$ obtained for current- and wave-alone tests is roughly 2.2 times the diameter of the marbles. For orthogonal wave-current flows, the $k_{n}$ value, when used in combination with the GrantMadsen (GM) model to reproduce the experimental apparent roughness, is found to be smaller than the measured current-alone and wave-alone $\mathrm{k}_{\mathrm{n}}$. Similar under-prediction of bottom roughness is also observed when the GM model is compared with a numerical study, thus supporting the conjecture that when the current is weak compared to the waves, simple theoretical models like GM are not sufficiently sensitive to the angle of wave-current interaction. Experiments with currents at angles of $60^{\circ}$ and $120^{\circ}$ to the wave direction yield apparent roughness smaller than the $90^{\circ}$ case, which is counter-intuitive since one would expect the mean flow to experience a stronger wave-induced turbulence when it is more aligned with the wave direction. This result indicates a possible contamination from waveinduced mass transport to the mean flow profile for non-orthogonal combined flow cases, and therefore highlights the need for other alternatives to the log-profile analysis when attempting to resolve $\mathrm{k}_{\mathrm{n}}$ from current velocity profiles from combined wave-current flows.
\end{abstract}

Keywords: wave-current interaction, boundary layer flow, bottom roughness

\section{INTRODUCTION}

Waves and currents are virtually always present simultaneously in coastal waters. Therefore, the hydrodynamics of these combined flows are of great interest to coastal scientists and engineers. In the past, most experimental studies focused on co-directional wave-current interaction, which is not commonly observed in the field. Recent works, e.g. Havinga (1992), Musumeci et al. (2006) and Madsen et al. (2010), hereafter referred to as MNLC, have provided new experimental data on the more physically realistic scenario of orthogonal or near-orthogonal wave-current interaction.

MNLC highlighted two important phenomena that could take place in orthogonal wave-current interaction. First, when the wave-induced bed forms are at an angle with the currents (other than codirectional or orthogonal orientation), the near-bottom mean flow tends to veer from its mainstream direction to become parallel to the ripple axis as the bottom is approached. This poses a problem to the use of the log-profile analysis in resolving bottom roughness, $\mathrm{k}_{\mathrm{n}}$, and shear velocity, $\mathrm{u}_{*_{\mathrm{c}}}$, since the method, as described in detail by Grant \& Madsen (1986), is formulated for steady unidirectional flows. Second, the mean flow changes direction across the entire water depth upon superposition of waves, due to the presence of wave-induced streaming or mass transport. This complicates the process of validating theoretical wave-current models, since $\mathrm{k}_{\mathrm{n}}$ is dependent on the angle of intersection between the flows and 2D roughness elements (Barrantes \& Madsen, 2000). Hence, more experimental studies involving orthogonal or near-orthogonal wave-current interaction over $3 \mathrm{D}$ fixed bottom roughness configurations are necessary.

The present study was conducted in the Hydraulics Laboratory at the National University of Singapore (NUS). Wave-alone experiments were performed in a flume, while current-alone and wavecurrent experiments were conducted in a wave basin, modified to allow currents to intersect with waves at three different angles. A summary of tests performed in this study is given in Table 1.

${ }^{1}$ Department of Civil \& Environmental Engineering, National University of Singapore, 1 Engineering Drive 2, E1A 0703, Singapore 117576 .

${ }^{2}$ R. M. Parsons Laboratory 48-216C, Department of Civil \& Environmental Engineering, Massachusetts Institute of Technology, Cambridge, MA 02139, USA. 


Table 1: Series of tests conducted in the present study
\begin{tabular}{|c|c|c|c|c|c|}
\hline Tests & $\begin{array}{c}\text { Water Depth } \\
(\mathrm{m})\end{array}$ & $\begin{array}{c}\text { Wave } \\
\text { period }(\mathrm{s})\end{array}$ & $\begin{array}{c}\text { Wave height } \\
(\mathrm{cm})\end{array}$ & $\begin{array}{c}\text { Nominal current } \\
\text { velocity (cm/s) }\end{array}$ & $\begin{array}{c}\text { Angle between waves } \\
\text { and currents (deg) }\end{array}$ \\
\hline Wave-alone & 0.4 & 1.6 & 10 & - & - \\
\hline Current-alone & 0.4 & - & - & 11 & - \\
\hline Wave-Current & 0.4 & $1.4,1.6$ & 10 & 11 & $60,90,120$ \\
\hline
\end{tabular}

\section{EXPERIMENTAL RESULTS}

\section{Case 1: Wave-alone over Ceramic Marbles}

Estimation of the bottom roughness for waves over ceramic marbles was done using the energy dissipation method. A detailed discussion of this methodology is given by Mathisen and Madsen (1996). This experiment was conducted in a wave flume $39 \mathrm{~m}$ long $\mathrm{x} 0.9 \mathrm{~m}$ wide $\mathrm{x} 0.9 \mathrm{~m}$ deep in the Hydraulics Lab at NUS. Water depth was $0.4 \mathrm{~m}$, wave period was $1.6 \mathrm{~s}$, and wave height was approximately $10 \mathrm{~cm}$. Surface elevation was measured with a capacitance-type wave gauge, mounted on a carriage that was moved over a stretch of $15 \mathrm{~m}$ along the flume. At $0.3 \mathrm{~m}$ intervals, the carriage was stopped to allow wave height measurements to be conducted. The positive $\mathrm{x}$-direction was assigned to be the direction of wave propagation. The first test was done over a bottom covered by a layer of ceramic marbles $\left(\mathrm{d}_{\text {mean }}=1.25 \mathrm{~cm}\right)$, and the subsequent test was for smooth bottom. This allows quantification of the sidewall effect, which would then be subtracted from the total dissipation, i.e.

$$
m_{r b}=m_{T r b}-m_{T s b}+m_{l}
$$

where $m$ is the attenuation slope, and subscript ' $\mathrm{T}$ ', ' $\mathrm{rb}$ ' and 'sb' denote total, rough bottom and smooth bottom, respectively. The last term on the right side of equation (1) represents laminar bottom dissipation and is added to account for the subtraction of energy dissipation over a smooth bottom (included in the second right hand term), which was absent in the rough bottom experiment.

The wave reflection coefficient is approximately $8 \%$. Despite this relatively small value, the influence of reflection on the estimation of wave energy dissipation can be quite significant. A plot of wave height variation along the flume is shown in Figure 1. It can be observed that there is a nearsinusoidal variation of wave height along the x-direction, and this could potentially lead to serious error of experimental determination of wave attenuation, if two points are arbitrarily picked to estimate the decay of the incident first harmonic wave height. The equation expressing the combined presence of incident (subscript ' $i$ ') and reflected (subscript ' $r$ ') waves can be written as:

$$
H(x)=\sqrt{{H_{i}}^{2}+{H_{r}}^{2}+2 H_{i} H_{r} \cos \left(2 k x+\phi_{i r}\right)}
$$

where $H(x)$ is the first harmonic wave height measured at location $\mathrm{x}, \mathrm{k}$ is the wave number and $\phi_{\text {ir }}$ is the phase difference between the incident and reflected waves. $H_{i}, H_{r}$ and $\phi_{i r}$ at a 'local' position were determined with equation (2) using least square fitting to measurement points which are within $0.6 \mathrm{~m}$ up- and down-wave of that location. These 'local' $H_{i}$ values were then plotted in the direction of positive $\mathrm{x}$ and a best linear fit was used to estimate the decay. The plots are shown in Figure 2 for both rough and smooth bottom cases. The wave height decay can be related to the wave energy dissipation using an expression given by Madsen (1993), shown here with some simplifications:

$$
\frac{d a_{i}}{d x}=-\frac{1}{4} \frac{f_{e}}{g C_{g}}\left(\frac{\omega}{\sinh k h}\right)^{3} a_{i}^{2}
$$

where $a_{i}$ is the first harmonic wave amplitude $\left(H_{i} / 2\right), f_{e}$ is the energy friction factor and $C_{g}$ is the wave group velocity. $f_{e}$ is related to the wave friction factor, $f_{w}$, through the following equation:

$$
f_{e}=f_{w} \cos \phi
$$




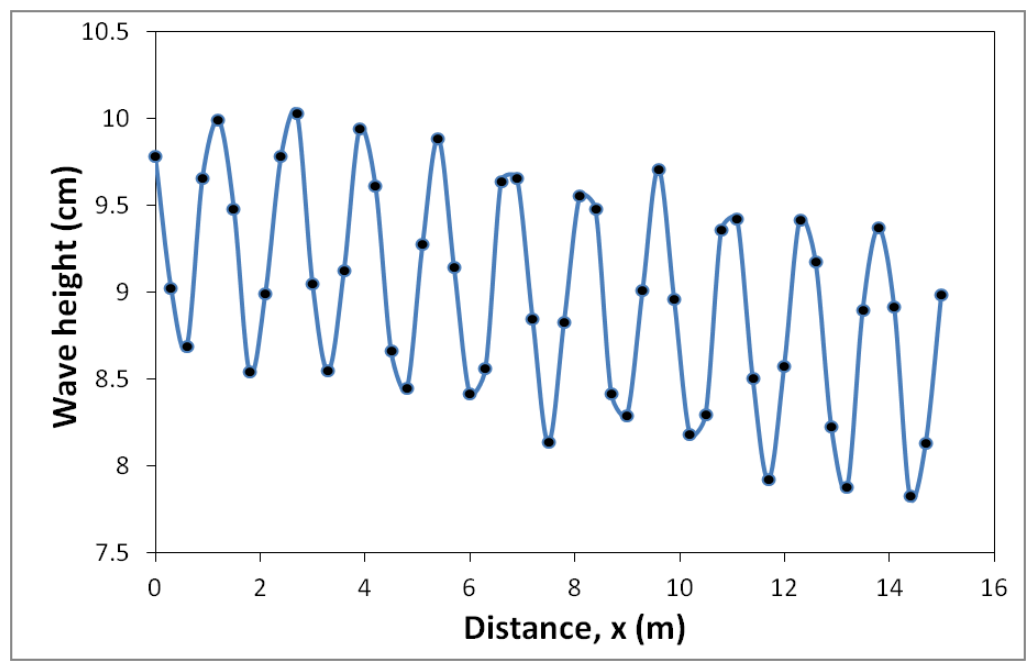

Figure 1: Wave height measurements (indicated by black dots) along the direction of wave propagation for rough bottom. A smooth curve is used to connect the dots to highlight the near-sinusoidal pattern of the wave height variation
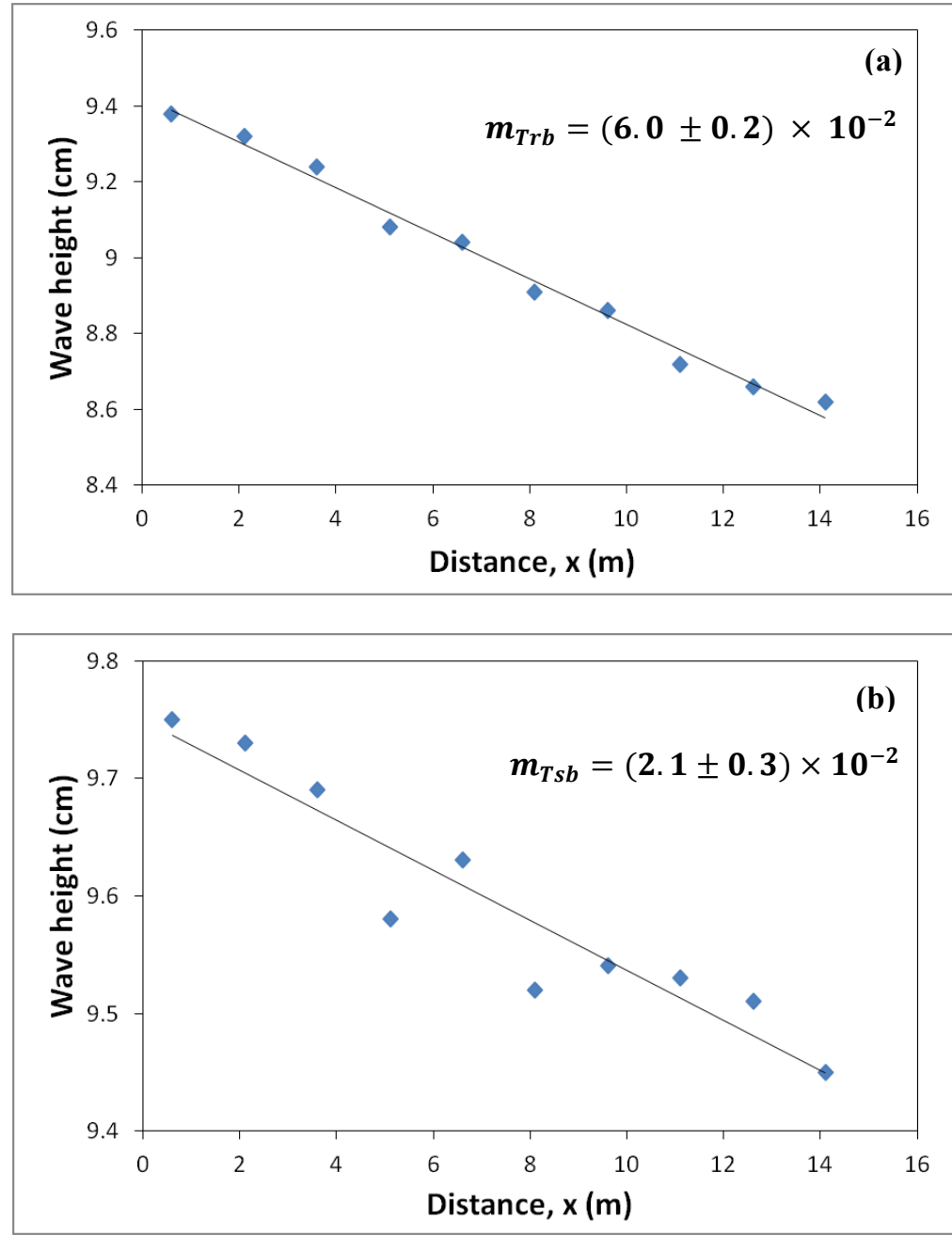

Figure 2: Decay of incident wave height, $H_{i}$ along the flume for (a) rough bottom (b) smooth bottom. The uncertainties are associated with one standard deviation. $m_{l}=3.3 \times 10^{-3}$ (theoretical prediction) 
where $\phi$ represents the phase difference between the bottom shear stress and the near-bottom wave orbital velocity predicted by linear wave theory. Madsen (1994) proposed the following equation for $\phi$ :

$$
\phi=\frac{\pi}{60}\left[11-2.0 \log _{10}\left(\frac{u_{b m}}{k_{n} \omega}\right)\right] \quad ; \quad 0.2<\frac{u_{b m}}{k_{n} \omega}<1000
$$

and for $f_{w}$ :

$$
f_{w}=\exp \left[7.02\left(\frac{u_{b m}}{k_{n} \omega}\right)^{-0.078}-8.82\right] \quad ; \quad 0.2<\frac{u_{b m}}{k_{n} \omega}<100
$$

With the above procedures, the bottom roughness, $k_{n}$, for waves alone (with error factor of one standard deviation) was estimated to be:

$$
k_{n}=k_{n w}=2.7 \mathrm{~cm} \times / \div 1.3
$$

\section{Case 2: Current-alone over Ceramic Marbles}

This experiment was performed in a wave-current basin in the Hydraulics Lab at NUS (Figure 3). A total of 3 current channels, designed for combined wave-current flows at $60^{\circ}, 90^{\circ}$ and $120^{\circ}$, were used in this preliminary current-alone test. Honeycomb filters consisting of $50 \mathrm{~cm}$-long, $5 \mathrm{~cm}$-diameter PVC pipes, were installed to ensure uniformity and directionality of inflows, and constant discharges throughout the experiments were checked using a flow meter. Water depth was $0.4 \mathrm{~m}$ for all experiments, and the concrete bottom was covered with a single layer of ceramic marbles of mean diameter $1.25 \mathrm{~cm}$. Velocity measurements were carried out using Acoustic Doppler Velocimeters (ADVs). Large distance from the current inlet, which is necessary for current boundary layer development, would ensure sufficient number of velocity measurement points being collected for roughness and shear stress analysis. The sampling duration at each elevation was 3 minutes (at a frequency of $200 \mathrm{~Hz}$ ). Approximately 25 elevations were occupied to obtain a well-defined velocity profile. Preliminary measurements of velocity profiles were also performed to establish regions of nearuniform current flow (shown as shaded areas in Figure 3), which would then form the spatial domain for detailed current-alone and wave-current measurements. The near-uniform flow region was approximately $0.25 \mathrm{~m}$ wide on both sides of the centerline of the current channel, and between $3.9 \mathrm{~m}$ and $5 \mathrm{~m}$ downstream from the current inlet. Figure $4 \mathrm{a}$ shows the uniformity of current velocities in the nearuniform flow region established for the ' $90^{\circ}$ ' channel, while Figure $4 \mathrm{~b}$ shows an example of a semi-log velocity profile obtained in this study. The log-profile analysis was used to estimate $\mathrm{k}_{\mathrm{n}}$ and $\mathrm{u}_{\mathrm{*}_{\mathrm{c}}}$. Briefly, this method involves fitting a straight line to the velocity data points at various elevations plotted on semi-log axes, and the slope and y-intercept of this best fit line yield $\mathrm{u}_{*_{\mathrm{c}}}$ and $\mathrm{k}_{\mathrm{n}}$, respectively.

To ensure consistency in the analysis, the same upper and lower limits of points used for least square fitting were adopted for all profiles. The upper limit, as described by Madsen et al. (2008), was based on 1/3 of the developing current boundary layer thickness proposed by Schlichting (1960), while the lower limit was taken as 2 times the roughness height (diameter), which was recommended by Mathisen \& Madsen (1996) in their study involving fixed artificial ripples. The upper limit was set to ensure points close to the edge of the boundary layer were dropped, while the lower limit was used to omit points influenced by local irregularities of the roughness elements. The theoretical bottom, i.e. the origin of the vertical coordinate, $z^{\prime}$, used in the log-profile analysis was fixed at $0.3 \mathrm{~d}_{50}$ below the top surface of the marbles for all rough bottom cases. The result for current-alone $k_{n}$ (with error factor of one standard deviation), which was obtained from measurements conducted in the 3 current channels at separate times (involving a total of 23 locations), is:

$$
k_{n}=k_{n c}=2.9 \mathrm{~cm} \times / \div 1.6
$$

This measured $k_{\mathrm{n}}$ is approximately $2.3 \mathrm{~d}_{50}$, which is within the range suggested in other studies, e.g. Negara (2009). In that experiment, the roughness element was natural gravel of size 3-6mm, and the author obtained a $k_{n}$ value of $12 \mathrm{~mm}$ from current-alone measurements. Another study by Yuan, 


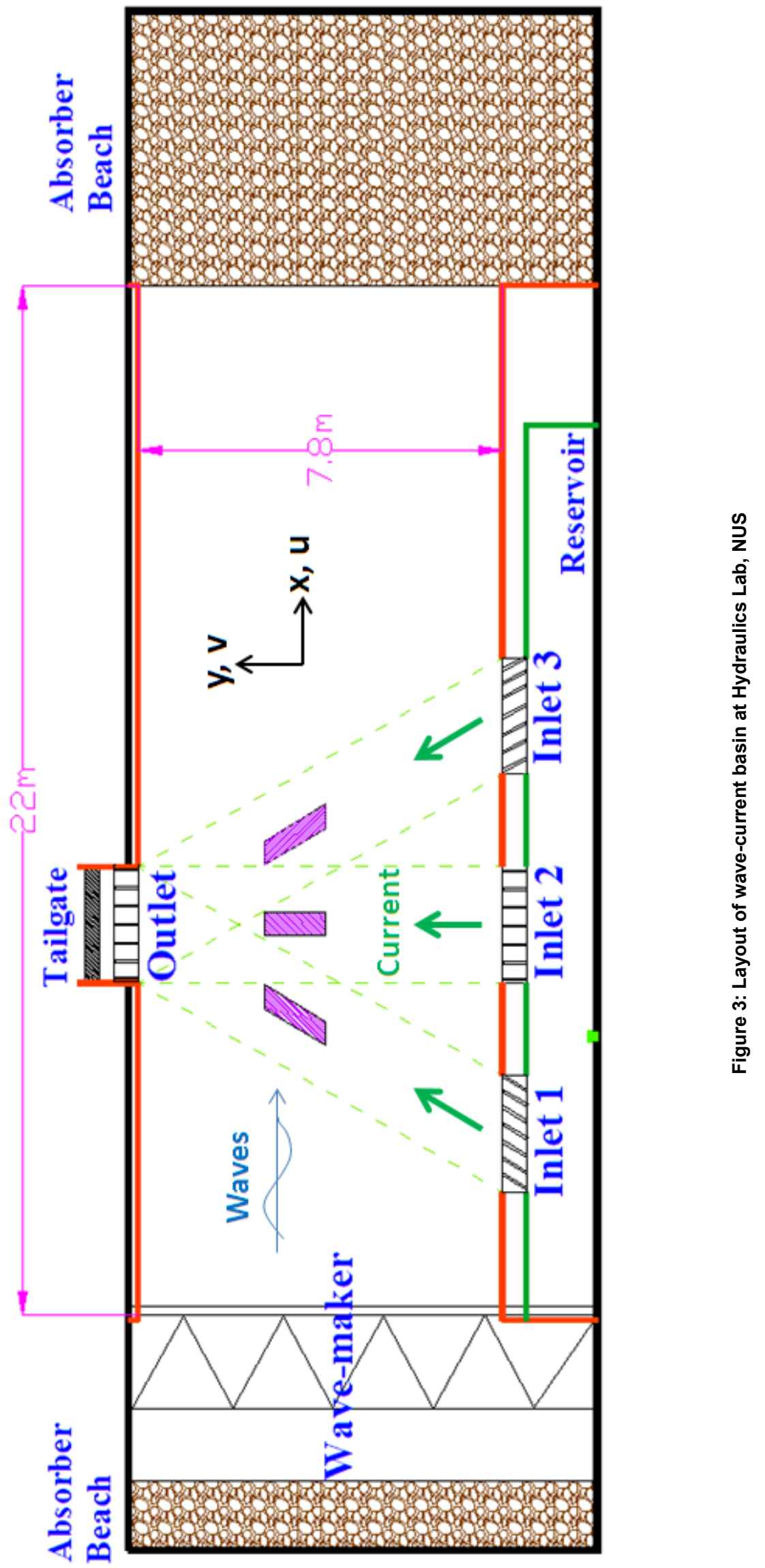



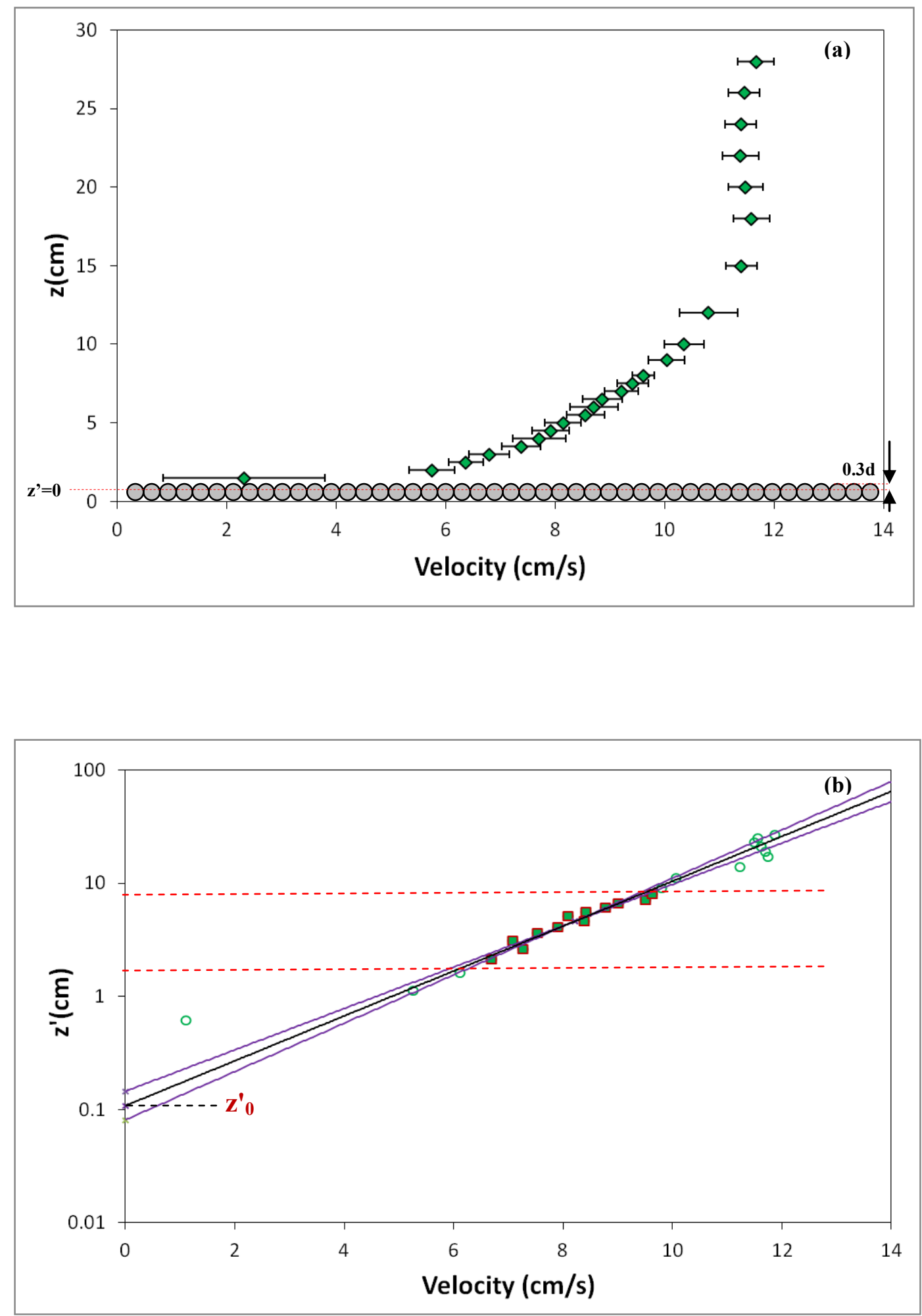

Figure 4: (a) Average current velocity profile within the near-uniform flow region for the ' $90^{\circ}$ ' current channel. Number of measurement locations used for mean calculation is 9 , and the error bars represent one standard deviation from the mean (b) Semi-log profile for current-alone flow, with green filled squares denoting measurement points used in the least square fitting. The red dashed lines indicate the upper and lower limits of the log-region, while the $y$-intercept of the log-profile is $z^{\prime}{ }_{0}=k_{n} / 30$. The purple lines show the results bounded by the $67 \%$ confidence interval for the slope, with the best linear fit intersecting the mid-point of the log-profile. 
Madsen and Chan (this issue), involving tests in an Oscillating Water Tunnel over the same ceramic marbles, gives a $k_{n}$ value of roughly $2 \mathrm{~cm}$. The results of both wave-alone and current-alone in this study support the findings of Mathisen \& Madsen (1996) that a single roughness length can be used for both currents and waves.

\section{Case 3: Combined Wave-Current Flow over Ceramic Marbles}

After the completion of current-alone tests, waves were added in the basin for combined wavecurrent experiments. Conditions for these flows are stated in Table 1. The experimental boundary Reynolds numbers, $R e_{*}$, computed with $\mathrm{k}_{\mathrm{n}}=2 \mathrm{~cm}$ and shown in Table 2, confirm that the wave boundary layer was fully rough turbulent.

Table 2: Near-bottom wave properties
\begin{tabular}{|c|c|c|c|c|c|}
\hline $\mathrm{T}(\mathrm{s})$ & $\mathrm{U}_{\mathrm{bm}}(\mathrm{cm} / \mathrm{s})$ & $\mathrm{A}_{\mathrm{bm}}(\mathrm{cm})$ & $A_{b m} / k_{n}$ & $R e_{w}=U_{b m} A_{b m} / v$ & $R e_{*}=k_{n} u_{* w m} / v$ \\
\hline 1.4 & 17.9 & 4.0 & 2.0 & 8900 & 1070 \\
1.6 & 19.6 & 5.0 & 2.5 & 12200 & 1100 \\
\hline
\end{tabular}

The experimental results show that the mean flow directions, regardless of the angle of interaction and bed roughness, increase by approximately 10 degrees. The positive x-direction is in the direction of wave propagation, while the positive $\mathrm{y}$-direction is perpendicular to the $\mathrm{x}$-axis and pointing towards the outlet. An example of the turning of mean flow is shown in Figure 5, where the initial current-alone flow (at $60^{\circ}$ to the positive $\mathrm{x}$-direction) experienced an increase in angle upon superposition of waves. This observed change of mean flow angle is associated with the wave-induced mass transport. Based on Stokes' mass transport prediction, the simple return current is approximately $1.60 \mathrm{~cm} / \mathrm{s}$ for our wave conditions. With a nominal current flow of about $11 \mathrm{~cm} / \mathrm{s}$ in our study, the addition of the Stokes mass transport velocity (in the direction opposite wave propagation) causes an angular deflection of the current of about 9 degrees, i.e. in fair agreement with our observations.

Comparison of experimental and theoretical prediction of mass transport for the $90^{\circ}$ case is shown in Figure 6. The wave-alone mass transport, while showing relatively close agreement with the theoretical model of Longuet-Higgins (1953) near the bottom, significantly deviates from this model when it approaches the upper part of the water column. This measured near-linear variation of the pure wave-induced mass transport current has also been observed in previous studies, e.g. Klopman (1994) and Musumeci et al. (2006). Nevertheless, upon superposition of waves, the mass transport becomes more homogenous throughout the water column. The reason for this dramatic change is unknown, but could be a consequence of extra turbulent mixing introduced by the external current. For $60^{\circ}$ and $120^{\circ}$ cases, the u-component mean velocity experiences a decrease and increase, respectively, in the nearsurface velocity when waves are present (Figure 7). It should be noted that the u-component of the $60^{\circ}$ current resembles a current following the waves, whereas the $120^{\circ}$ current has a u-component current that is opposing the waves. Hence, the experimental results obtained in this study are consistent with the observations for following and opposing collinear wave-current interaction, e.g. Klopman (1994).

The analysis of bottom roughness in the combined wave-current flow was done using the GM model (Madsen, 1993). First, $\mathrm{k}_{\mathrm{na}}$ was estimated from the best linear fit of measured current velocity on a semi-log plot. An iteration was then conducted in order to obtain a $\mathrm{k}_{\mathrm{n}}$ value which, when used as an input into the GM model, yields a $\mathrm{k}_{\mathrm{na}}$ value that matches the experimental $\mathrm{k}_{\mathrm{na}}$. The results are shown in Table 3. Comparing the results with the measured $k_{n}$ for current-alone, the values for $90^{\circ}$ case are smaller than the current-alone case. A possible explanation is that the simple GM model has overaccounted for the effect of wave-induced turbulence on the mean flow, when the angle is large between waves and currents. In the GM model formulation, the wave-induced turbulence for combined flow boundary layer is mainly influenced by the maximum wave shear velocity, $\mathbf{u}_{{ }_{\mathrm{wm}} \mathrm{wm}}$, when the waves are much stronger than the currents. This parameter is independent of the angle between waves and currents, which explains the insensitivity of the GM model to angle between waves and currents for weak current conditions. 


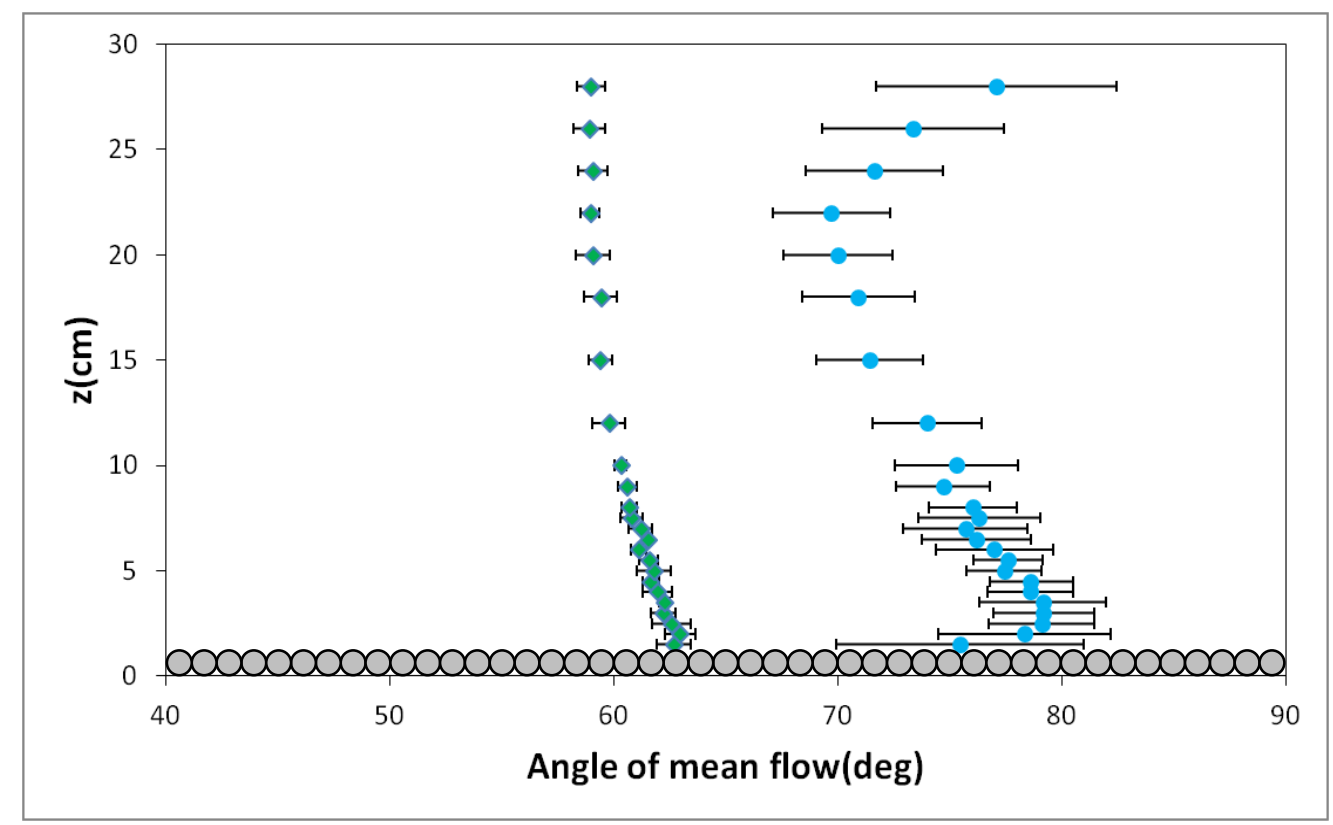

Figure 5: Average angle of mean flows for $60^{\circ}$ rough bottom experiment. Green diamond denotes currentalone, Blue circle denotes wave-current. Number of measurement locations used for mean calculation is 7 , and the error bars represent one standard deviation from the mean

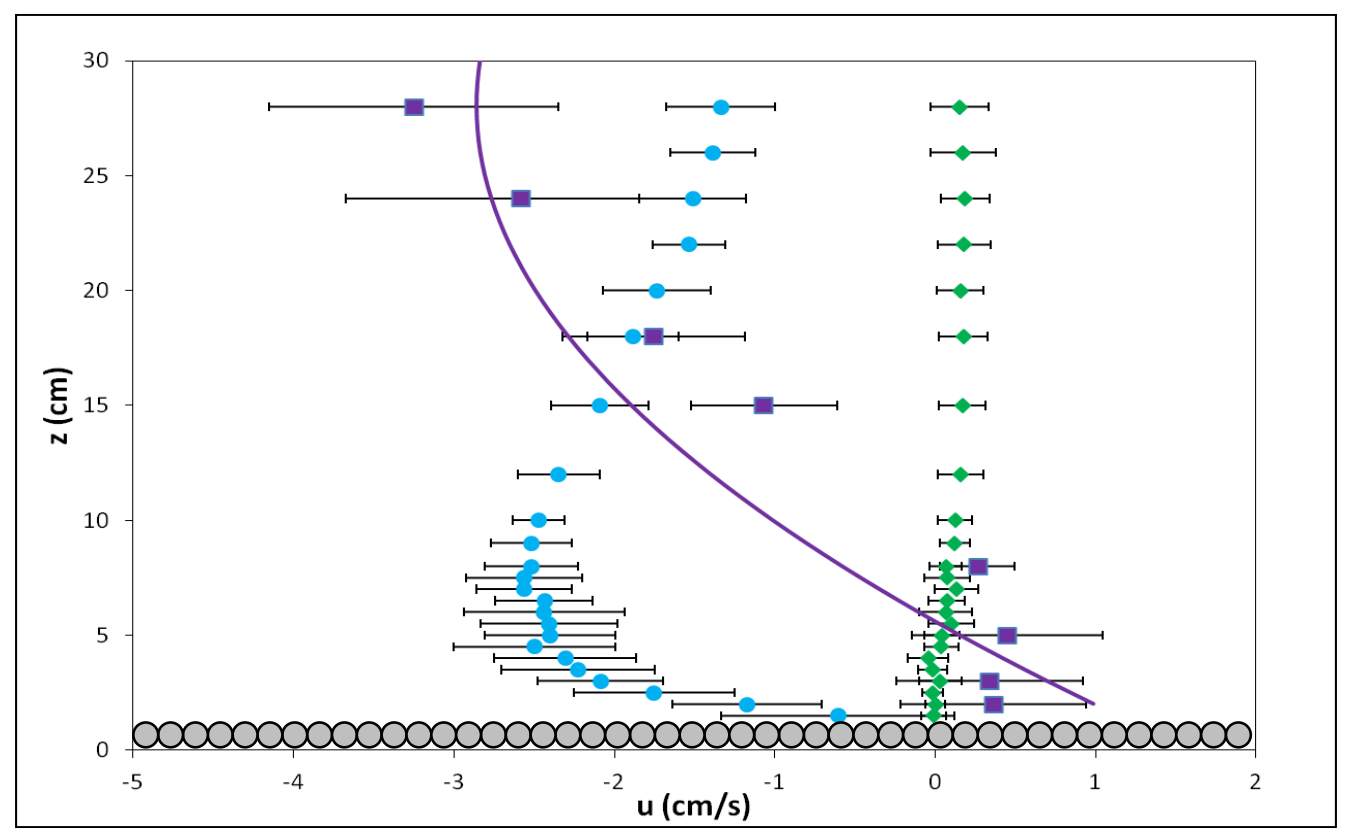

Figure 6: Comparison of current-alone (green diamond), wave-alone (purple square) and $90^{\circ}$ combined wavecurrent flows (blue circle) along the x-direction, with the theoretical prediction of Longuet-Higgins (1953) shown in full purple line. $T=1.6 \mathrm{~s}$ for wave-alone and wave-current tests. Number of measurement locations used for mean calculation is 7 , and the error bars represent one standard deviation from the mean 

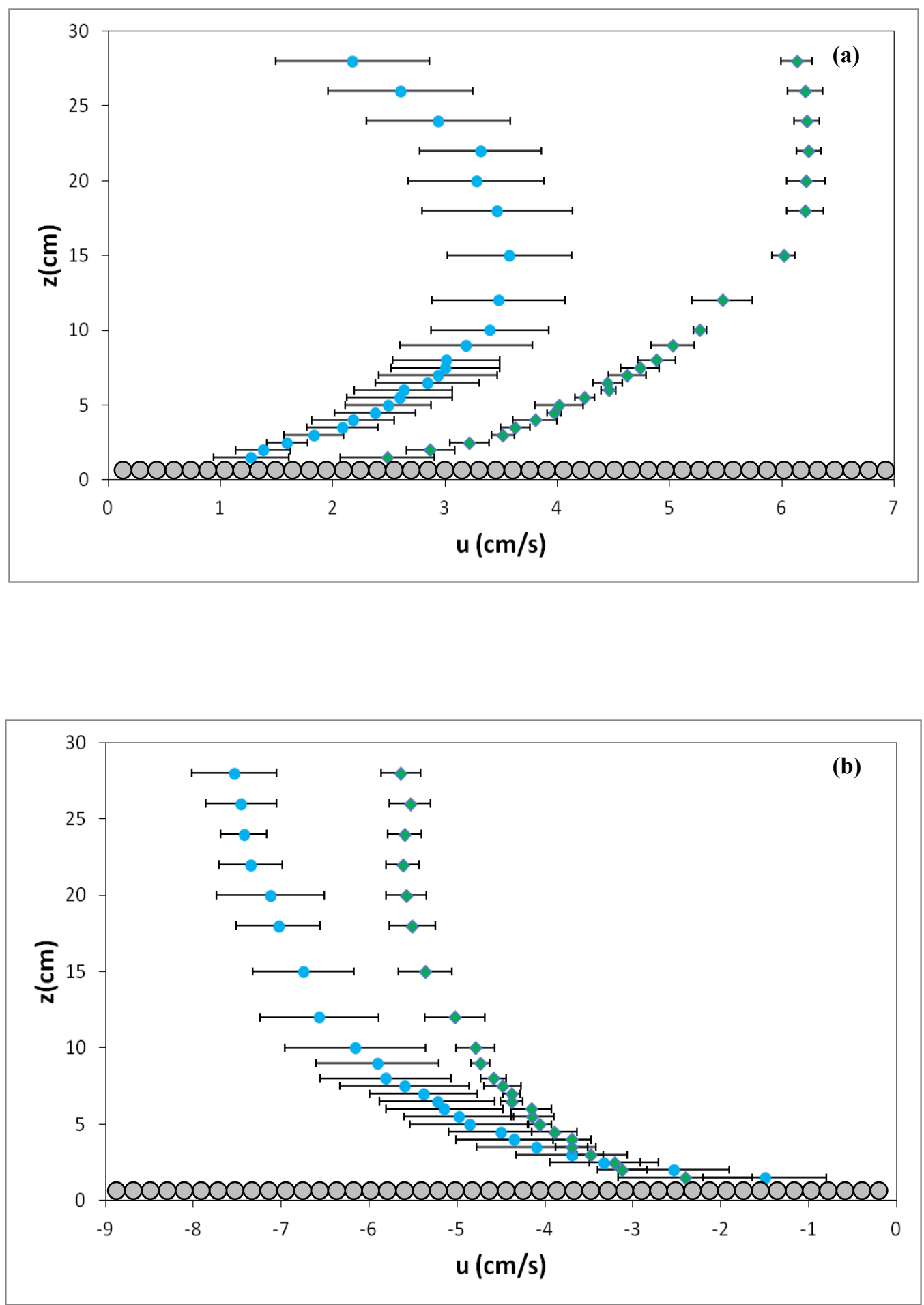

Figure 7: u-component mean velocity $(T=1.6 \mathrm{~s})$ for (a) $60^{\circ}$ (b) $120^{\circ}$ wave-current interaction; Green diamond denotes current-alone, Blue circle denotes wave-current. Number of measurement locations used for mean calculation is 7 , and the error bars represent one standard deviation from the mean 
To provide a more quantitative support for the above argument, we compare the predictions of the GM model with the numerical results of Davies et al. (1988). The parameters are chosen as those used in Davies et al.'s calculations, i.e. $T=8 \mathrm{~s}, h=10 \mathrm{~m}, U_{b m}=100 \mathrm{~cm} / \mathrm{s}, k_{n}=15 \mathrm{~cm}$ and $u_{*_{c}}=5.8 \mathrm{~cm} / \mathrm{s}$. Figure $8 \mathrm{a}$ shows that when the angle between wave and current is $0^{\circ}$, i.e. co-directional wave-current flow, current velocity profiles predicted with both models are in good agreement. However, when the angle is increased to $90^{\circ}$ (Figure $8 \mathrm{~b}$ ), the change in GM model is relatively small compared to the Davies et al.'s model. In order for both models to predict the same apparent roughness, the input $\mathrm{k}_{\mathrm{n}}$ into the GM model has to be reduced by about $30 \%$ from its actual value. This reduction is in fair agreement with the observed under-prediction of $\mathrm{k}_{\mathrm{n}}$ in the present study, in particular for $\mathrm{T}=1.4 \mathrm{~s}$ case.

For the $60^{\circ}$ case, the $\mathrm{k}_{\mathrm{n}}$ value is found to be the smallest. The presence of wave-induced mass transport, which has the smallest velocity at the bottom before increasing to its maximum magnitude at around $7 \mathrm{~cm}(\sim 3 \mathrm{~cm} / \mathrm{s}$ opposite the direction of wave propagation, as shown in Figure 6$)$, can potentially change the slope of the log-profile. Since a decrease of velocity at the top of the log-profile can be expected due to mass transport, it is not surprising that an underestimate of the shear velocity and apparent roughness is observed here. This conceptual model for contamination of the external current profile by wave-induced mass transport is illustrated in Figure 9. Figure 9a shows a perfect log-profile for an external current, whereas the component of the wave-induced mass transport (here taken as the projection of the mass transport current obtained for orthogonal wave-current flows, i.e. similar in trend to that shown in Figure 6) in the direction of the external current is shown in Figure 9b. Combining these two currents produces the velocity profile shown in Figure 9c, and results in a decrease in the roughness inferred from log-profile analysis relative to the roughness obtained from the perfect external current profile. The roughness decrease estimated from this example is of the order $20 \%$. One would, however, expect that similar considerations of current profile contamination by wave-induced mass transport would lead to an overestimate of the bottom roughness for the $120^{\circ}$ case. This is, as seen from the results shown in Table 3 , true for the $\mathrm{T}=1.6 \mathrm{~s}$ case but not for the $\mathrm{T}=1.4 \mathrm{~s}$ case.

Based on the argument above, it is expected that the v-component current velocity profiles, i.e. in the direction perpendicular to the waves, should be relatively free from the influence of mass transport. A log-profile analysis was conducted using the v-component current and showed no significant change in the results, indicating that this method is not able to remove the wave-induced mass transport contamination of the external current profile. This also suggests that there could be additional influences on the velocity profiles, apart from the wave-induced mass transport. More experimental data are therefore needed to gain further insight into this problem, as well as to develop an alternative to the log-profile method when attempting to resolve $\mathrm{k}_{\mathrm{na}}$ and $\mathrm{u}_{*_{\mathrm{c}}}$ for combined wave-current experiments.

\begin{tabular}{|c|c|c|c|c|}
\hline $\begin{array}{c}\text { Angle between } \\
\text { waves and } \\
\text { currents (deg) }\end{array}$ & $\mathrm{T}(\mathrm{s})$ & $\mathrm{k}_{\mathrm{na}}(\mathrm{cm})$ & $\mathrm{u}_{*_{\mathrm{C}}}(\mathrm{cm} / \mathrm{s})$ & $\mathrm{k}_{\mathrm{ncw}}(\mathrm{cm})$ \\
\hline 60 & $\begin{array}{l}1.4 \\
1.6\end{array}$ & $\begin{array}{l}4.01 \times / \div 1.5 \\
3.93 \times / \div 1.6\end{array}$ & $\begin{array}{l}0.94 \pm 0.10 \\
1.02 \pm 0.12\end{array}$ & $\begin{array}{ccc}0.57 & \times / \div 1.8 \\
0.56 & \times / \div 2.0\end{array}$ \\
\hline 90 & $\begin{array}{l}1.4 \\
1.6\end{array}$ & $\begin{array}{l}7.82 \times / \div 1.2 \\
5.77 \times / \div 1.9\end{array}$ & $\begin{array}{l}1.23 \pm 0.06 \\
1.06 \pm 0.13\end{array}$ & $\begin{array}{lll}1.92 & \times / \div & 1.3 \\
1.06 & \times / \div & 2.4\end{array}$ \\
\hline 120 & $\begin{array}{l}1.4 \\
1.6\end{array}$ & $\begin{array}{l}6.41 \times / \div 1.5 \\
7.54 \times / \div 1.4\end{array}$ & $\begin{array}{l}1.07 \pm 0.09 \\
1.05 \pm 0.18\end{array}$ & $\begin{array}{lll}1.45 & \times / \div 1.7 \\
1.28 & \times / \div 1.8\end{array}$ \\
\hline
\end{tabular}

\section{CONCLUSIONS}

A series of experiments involving current-alone, wave-alone and combined wave-current flows were conducted in a flume and a wave basin in the Hydraulics Lab at NUS. The following conclusions can be drawn from this study: 

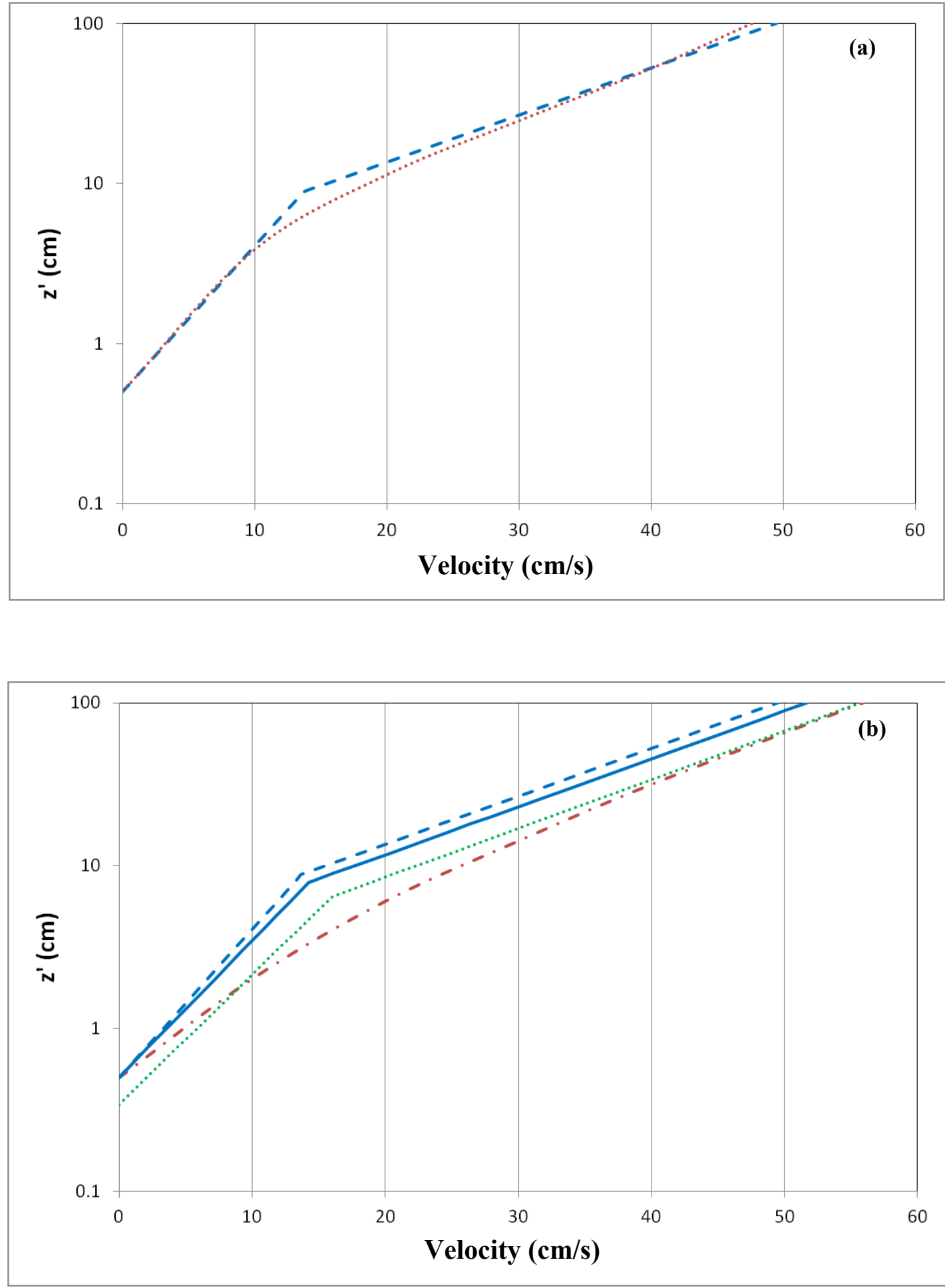

Figure 8: (a) Comparison between GM model (blue dashed line) and Davies et al.'s model (red dotted line) for $0^{\circ}$ interaction; (b) Comparison between GM model and Davies et al.'s model for $90^{\circ}$ interaction. $0^{\circ} \mathrm{GM}$ : blue dashed line; $90^{\circ} \mathrm{GM}$ : blue full line; $90^{\circ}$ Davies et al.'s model: red dashed-dotted line; $90^{\circ} \mathrm{GM}$ with adjusted $\mathrm{k}_{n}$ : green dotted line 

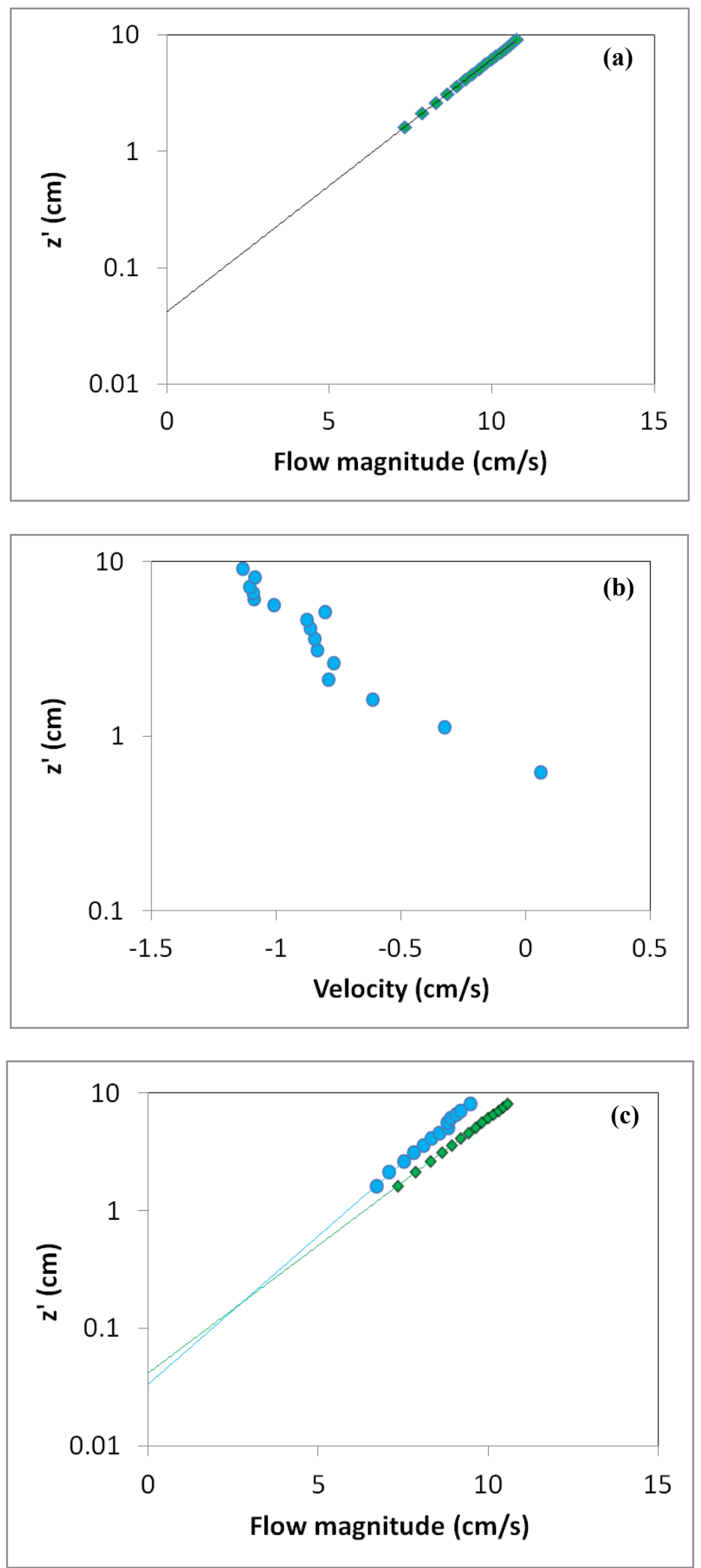

Figure 9: (a) An example of a 'perfect' log-profile for an external current at $60^{\circ}$ with the direction of the wave propagation (b) wave-induced mass transport (based on a measurement obtained in this study) projected onto the direction of the external current (c) Comparison of the log-profile contaminated by mass transport (blue circle) with the original 'perfect' log-profile (green diamond) 
- When waves and currents are present simultaneously in a basin, the angle of mean flow increases, i.e. towards the direction of the wave paddles, due to the presence of wave-induced mass transport. The increase, generally of the order 10 degrees for the range of angle cases performed in this study, is in fair agreement with the prediction obtained from Stokes' mass transport theory.

- The wave-alone mass transport showed a linearly-increasing trend in the direction opposite the wave propagation, which is different from the prediction of Longuet-Higgins (1953). This trend changed dramatically into near uniform distribution when an orthogonal current was superimposed on the waves. The reason for this drastic change is not clear, but it could be the result of an increase in turbulent mixing due to the presence of the external current.

- The $\mathrm{k}_{\mathrm{n}}$ value, when used in combination with the Grant-Madsen model to predict the experimental apparent roughness, was found to be smaller than the measured current-alone $\mathrm{k}_{\mathrm{n}}$ for the $90^{\circ}$ wave-current interaction. This result is in agreement with the comparison between the GM model and numerical results of Davies et al. (1988), thus supporting the conjecture that simple analytical models, like the GM model, do not accurately account for the effect of angle between waves and currents in wave-current interaction for weak current cases.

- For $60^{\circ}$ and $120^{\circ}$ experiments, the experimental apparent roughness, $\mathrm{k}_{\mathrm{na}}$, obtained from the log-profile analysis, is generally smaller than the value obtained in the $90^{\circ}$ case. A conceptual model of how the wave-induced mass transport will lead to an underestimation of the experimental $\mathrm{k}_{\mathrm{na}}$ for $60^{\circ}$ is proposed. Based on a similar argument, the mass transport should cause an increase in the roughness prediction for the $120^{\circ}$ case, which is observed for the $\mathrm{T}=1.6 \mathrm{~s}$ case but not for the $\mathrm{T}=1.4 \mathrm{~s}$ case.

- Use of the current velocity component perpendicular to the wave direction, which in principle should be free from mass transport contamination, fails to improve the results obtained from log-profile fitting of the measured mean velocity.

Additional experimental data on combined near-orthogonal wave-current flows are needed to explain our contradicting observations and the dramatic effect due to superposition of an external orthogonal current on the wave-induced mass transport.

\section{ACKNOWLEDGMENTS}

The authors gratefully acknowledge the financial support of the National Research Foundation (NRF) of Singapore through the Singapore-MIT Alliance for Research and Technology's (SMART) Center for Environmental Sensing and Modeling (CENSAM). KYL acknowledges the support received from Singapore's Ministry of Education through a SMA3 Fellowship.

\section{REFERENCES}

Barrantes, A.I., O.S. Madsen. 2000. Near-bottom flow and flow resistance for currents obliquely incident to two-dimensional roughness elements. Journal of Geophysical Research, 105(C11), 26,253-26,264.

Davies, A.G., R.L. Soulsby, H.L. King. 1988. A numerical model of the combined wave and current bottom boundary layer. Journal of Geophysical Research, 93(C1), 491-508.

Grant, W.D., O.S. Madsen. 1986. The continental shelf bottom boundary layer. Annual Review of Fluid Mechanics, 18, 265-305.

Havinga, F.J. 1992. Sediment Concentration and Sediment Transport in Case of Irregular NonBreaking Waves with a Current. Part E. Technical Report. Delft University of Technology, Netherlands.

Klopman, G. 1994. Vertical structure of the flow due to waves and currents. Delft Hydraulics Progress Report H 840.30, Part II. 
Longuet-Higgins, M. S. 1953. Mass transport in water waves. Philos. Trans. R. Soc. London, Ser. A, $245,535-581$.

Madsen, O.S. 1993. Sediment Transport on the Shelf. Draft document, Ralph M. Parsons Laboratory, Massachusetts Institute of Technology, Cambridge, M.A.

Madsen, O. S. 1994. Spectral wave-current bottom boundary layer flows. Proceedings $24^{\text {th }}$ International Conference on Coastal Engineering, ASCE, 384-398.

Madsen, O.S., S. Kularatne, H.F. Cheong. 2008. Experiments on bottom roughness experienced by currents perpendicular to waves. Proceedings 31st International Conference on Coastal Engineering, ASCE, 1, 845-853.

Madsen, O.S., A.S. Negara, K.Y. Lim, H.F. Cheong. 2010. Near-bottom flow characteristics of currents at arbitrary angle to $2 \mathrm{D}$ ripples. Proceedings $32^{\text {nd }}$ International Conference on Coastal Engineering, ASCE, Paper \#: Current. 36

Mathisen, P.P., O.S. Madsen. 1996. Waves and currents over a fixed rippled bed: 1. Bottom roughness experienced by waves in the presence and absence of currents. Journal of Geophysical Research, 101(C7), 16533-16542.

Musumeci, R. E., L. Cavallaro, E. Foti, P. Scandura, P. Blondeaux. 2006. Waves plus currents crossing at a right angle: Experimental investigation. Journal of Geophysical Research, 111, C07019, doi:10.1029/2005JC002933.

Negara. A.S. 2009. Experimental study of turbulent current over fixed 2D and 3D bottom roughness. M. Eng. Thesis, Department of Civil and Environmental Engineering, National University of Singapore.

Schlichting, H. 1960. Boundary Layer Theory, fourth edition. McGraw-Hill, New York.

Yuan, J., O.S. Madsen, E.S. Chan. 2012. Experimental study of turbulent oscillatory boundary layers in a new oscillatory water tunnel. Proceedings $33^{\text {rd }}$ International Conference on Coastal Engineering, ASCE. 